\title{
Monitoramento e modelagem da operação de elementos internos de sombreamento em escritórios: uma revisão de literatura
}

\author{
Monitoring and modelling the operation of internal \\ shading devices in offices: a literature review
}

\section{Mateus V. Bavaresco Enedir Ghisi}

\section{Resumo \\ A}

influência do comportamento dos usuários no desempenho termoenergético e lumínico de edificações vem sendo discutida na literatura. Em relação aos ajustes de elementos internos de sombreamento não automatizados em escritórios, cabe ao usuário administrar o balanço entre o aproveitamento de iluminação natural e a redução de radiação solar. Desta forma, o objetivo deste estudo é revisar a literatura nacional e internacional dos últimos dez anos (de 2009 a 2019) a fim de sintetizar o conhecimento produzido em relação aos monitoramentos e modelagem de ajustes de elementos internos de sombreamento em escritórios. Identificaram-se diversos métodos adequados para monitorar o comportamento dos usuários; tais métodos resultam tanto em informações subjetivas (preferências pessoais) quanto objetivas (variável ambiental impactante). O desafio nessa área é combinar as diferentes informações para modelar os comportamentos dos usuários de maneira realística e precisa. Concluiu-se que avanços no monitoramento e modelagem dos comportamentos aprimoram as práticas de simulação computacional e de elaboração de sistemas de automação predial centrados nos usuários. Por fim, ressalta-se que avaliar continuamente os padrões de comportamento dos usuários permite obter informações sobre os sistemas automatizados a fim de adequá-los durante sua vida útil.

Palavras-chave: Elementos internos de sombreamento. Comportamento de usuário. Simulação computacional. Eficiência energética. Países em desenvolvimento.

\begin{abstract}
The influence of user behaviour on the performance of buildings has been discussed in the literature. Regarding the operation of non-automated internal blinds/shades in offices, it is up to the occupant to balance the use of daylight as well as the reduction of incident solar radiation by adjusting the internal blinds/shades throughout the occupied period. This study aims to review the national and international literature of the last ten years (from 2009 up to 2019) to summarise the knowledge produced so far regarding the monitoring and modelling of internal blinds/shades operation in offices. Several suitable methods have been identified to monitor users' behaviour; such methods result in both subjective (personal preferences) and objective (affecting environmental variables) information. The challenge in this area is to combine different information to model user behaviour realistically and accurately. It was concluded that advances in the monitoring and modelling of behaviours improve the practices of computer simulation and the development of usercentred building automation systems. Finally, it is noteworthy that continuously monitoring user behaviour patterns allows to obtain feedback on automated systems in order to enhance them during their lifespan.
\end{abstract}

Keywords: Internal blinds/shades. User behaviour. Computer simulation. Energy efficiency. Developing countries. 


\section{Introdução}

A influência do comportamento dos usuários no desempenho energético de edificações tem sido amplamente reconhecida (BALVEDI; GHISI; LAMBERTS, 2018; D’OCA; HONG; LANGEVIN, 2018; STAZI; NASPI; D'ORAZIO, 2017; YAN et al., 2017). Ao se avaliar o uso total de energia em edificações, Yoshino, Hong e Nord (2017) concluíram que dentre os seis fatores mais impactantes no consumo energético, três estão relacionados às atividades dos usuários e podem influenciar tanto quanto, senão mais, que os demais. Desta forma, é necessário compreender de modo mais aprofundado os fatores que motivam os ajustes de sistemas de edificações (janelas, persianas, aparelhos de ar-condicionado, lâmpadas, etc.). Com informações mais conclusivas sobre esses aspectos, modelos que representam o comportamento dos usuários de forma precisa podem melhorar as práticas de simulação computacional, tornando-as mais precisas, e também facilitar a obtenção de edificações centradas nos usuários. Por edificações centradas nos usuários, entende-se tanto o design que considere as preferências dos usuários quanto o controle dos sistemas para que mantenham as condições internas em limites confortáveis.

Em relação ao controle dos sistemas, os ajustes de elementos internos de sombreamento (EIS) podem balancear o aproveitamento de iluminação natural e a incidência de radiação solar no interior das edificações (LIU; YAO; MCCLOY, 2014). Nesse sentido, modelos ideais de controle visando maximizar o aproveitamento de iluminação natural e, ao mesmo tempo, minimizar as trocas térmicas desvantajosas foram propostos (YAO, 2014). Entretanto, modelos ideais, baseados apenas em aspectos de física da edificação, falham na representação dos usuários dos espaços, que não se comportam de maneira mecânica. Além disso, se esses tipos de modelo servirem como controle para sistemas automatizados, baixos níveis de aceitação por parte dos usuários podem ser alcançados. Desta forma, é necessário ampliar o conhecimento sobre os aspectos impactantes aos ajustes dos EIS, principalmente em locais onde esses estudos ainda são escassos.

Em relação à obtenção de conhecimento sobre comportamento de usuários em edificações, ressalta-se que não há normas ou recomendações específicas para a realização de estudos de campo e nem para a elaboração de modelos para representar cada ação dos usuários (O’BRIEN; GUNAY, 2014; WAGNER; O'BRIEN; DONG, 2017). Entretanto, como discutido por Gilani et al. (2016), também não é claro nem se a comunidade científica irá normatizar essas práticas nem se essa normatização é necessária. Apesar de dificultar a comparação de resultados obtidos em diferentes locais, a inexistência de exigências específicas para os experimentos permite aplicar grande variabilidade de métodos. Essa característica favorece a obtenção de informações inesperadas e garante maior autonomia aos responsáveis pelos estudos para aplicar os recursos disponíveis no local. Desta forma, é importante sintetizar o que já foi feito em diferentes locais a fim de informar outros pesquisadores ou profissionais da área sobre a ampla possibilidade de se avaliar o comportamento dos usuários em campo.

Apesar de diversas tecnologias terem sido apresentadas como viáveis para os estudos de comportamento de usuário em edificações (BAVARESCO et al., 2019a; WAGNER; O'BRIEN; DONG, 2017; YAN et al., 2017), equipamentos baseados em Internet das Coisas ou outras inovações tecnológicas não estão sempre disponíveis para realizar monitoramentos em campo. Considerando-se o cenário de países em desenvolvimento, em especial, onde inovações tecnológicas nem sempre estão disponíveis para monitorar o comportamento dos usuários, alternativas de baixo custo podem suprir as necessidades locais e avançar os estudos nessa área. Nesse sentido, Bavaresco e Ghisi (2019) propuseram uma estrutura de baixo custo para monitorar os ajustes dos elementos internos de sombreamento em edificações de escritório, avaliando-se aspectos subjetivos que influenciam os ajustes. O principal aspecto apresentado pelos autores é a possibilidade de utilizar modelos criados em outras pesquisas para realizar simulações computacionais considerando-se os aspectos subjetivos relacionados ao local de estudo. Essas avaliações são importantes, pois possibilitam estudar os impactos de diferentes estratégias de sombreamento interno em edificações de escritório para garantir maiores níveis de satisfação aos usuários. Esses avanços são necessários para minimizar ocorrências de eventos como os encontrados por Costa (2011), que ao avaliar a ergonomia de escritórios em repartições públicas brasileiras, observou que, em alguns casos, as janelas são vedadas internamente com papel. Além de barrar o aproveitamento de iluminação natural e a vista para o exterior, esse tipo de adequação reforça a ideia de que a operação dos sistemas das edificações está condicionada à aceitação por parte dos usuários. Portanto, mesmo que se instale um sistema automatizado oneroso para controlar as persianas de uma edificação, o retorno em relação ao conforto dos usuários não é garantido. É necessário, portanto, conhecer as preferências daqueles que utilizarão os sistemas propostos a fim de adequálos a esses limites e buscar maior aceitação por parte dos usuários. 
Desta forma, esta revisão de literatura visa aprofundar os estudos nessa área, com o objetivo de apresentar técnicas de monitoramento e modelagem de ajustes de EIS. Além disso, são apresentados os programas computacionais empregados em simulações termoenergéticas e lumínicas considerando-se modelos de comportamento de usuário e as relações do conhecimento produzido com a criação de sistemas automatizados em edificações. Para sintetizar o conhecimento produzido até aqui e favorecer o avanço nessa área, a literatura nacional e internacional dos últimos dez anos (de 2009 a 2019) foi revisada. Como a literatura nacional é mais escassa quando comparada à internacional, espera-se que essa revisão de literatura favoreça a elaboração de futuros estudos em diferentes regiões brasileiras, empregando-se métodos de monitoramento e modelagem adequados à realidade de cada local.

\section{Busca sistemática de literatura}

Para aprofundar o conhecimento sobre os métodos empregados para monitorar e modelar os ajustes dos elementos internos de sombreamento em edificações de escritório, foram realizadas buscas sistemáticas em duas das principais bases de dados de produção científica: Scopus e Google Acadêmico. Selecionou-se a literatura dos últimos dez anos (de 2009 a 2019) para conduzir a revisão. Apesar de similares às do Scopus, as buscas no Google Acadêmico foram realizadas utilizando-se termos em português a fim de encontrar estudos nacionais. Os termos utilizados em ambas as bases de dados foram:

(a) Scopus: (blind OU shade) E ((occupant OU user) $\mathbf{E}$ behavio*) E office; e

(b) Google Acadêmico: (cortina OU persiana) E ("comportamento do usuário") E escritório.

A partir da busca no Scopus, 54 documentos foram encontrados; no Google Acadêmico, 43 documentos foram encontrados. Entretanto, destaca-se que a literatura internacional apresenta abordagens e resultados mais específicos em relação aos ajustes dos EIS quando comparada à amostra da literatura nacional. A maioria dos estudos nacionais, apesar de apresentarem os termos pesquisados, não tratavam especificamente do assunto em questão. Desta forma, a maior parte dos estudos revisados foram conduzidos fora do Brasil. Ao longo desta revisão de literatura, são apresentadas informações sobre as técnicas de monitoramento dos ajustes de EIS, as abordagens utilizadas para modelar os padrões de operação, especificidades sobre os programas computacionais utilizados em simulações e, por fim, a importância deste tópico para a criação de sistemas automatizados. Espera-se que a experiência internacional nessa área sirva como base para o desenvolvimento de mais estudos no Brasil.

\section{Monitoramento}

Por não haver normas ou recomendações específicas para a realização de estudos sobre comportamento de usuário em edificações, diferentes técnicas de monitoramento são apresentadas na literatura. A inexistência de normas dificulta a comparação entre os resultados obtidos em diferentes avaliações; entretanto, o caráter subjetivo do tópico em estudo favorece a aplicação de vários métodos, e informações adicionais, muitas vezes inesperadas, podem ser obtidas com a aplicação de diferentes abordagens. Tratando-se especificamente de avaliações sobre os ajustes de elementos internos de sombreamento (EIS), a literatura confirma o amplo campo de possibilidades para avaliação, tanto em relação aos métodos em si quanto em relação às subjetividades na aplicação de cada um deles.

Outro aspecto importante a ser considerado nessa área é que muitos trabalhos são baseados em monitoramentos já conduzidos e apresentados na literatura, tanto pelos próprios autores quanto por terceiros (BAVARESCO et al., 2019b; GILANI et al., 2016; GUNAY; O’BRIEN; BEAUSOLEIL-MORRISON, 2016; JAKUBIEC; REINHART, 2011; OUF; GUNAY; O’BRIEN, 2019). A maioria dos estudos contextualiza as abordagens utilizadas para monitorar os ajustes dos EIS e criar padrões coerentes para simulação computacional. Utilizar resultados de monitoramentos anteriores facilita a elaboração de novas hipóteses e buscas por respostas a questões ainda não resolvidas, principalmente considerando-se que avaliações em campo tendem a ser dispendiosas.

Nesta seção, são apresentados detalhes sobre os principais métodos empregados nas avaliações. Espera-se que a difusão dessas possibilidades facilite a realização de novos estudos em diferentes cidades brasileiras. 


\section{Observações em campo: Walkthroughs}

Walkthroughs consistem em visitas às edificações para identificar problemas ou falhas no funcionamento de sistemas a fim de reportá-los aos gestores e melhorar o desempenho das edificações. De maneira geral, walkthroughs podem ser considerados como inspeções visuais para obter um panorama geral do desempenho de edifícios; ressalta-se que os responsáveis podem utilizar materiais e tecnologias (blocos de anotações, câmeras fotográficas, etc.) para registrar eventos importantes durante as visitas. Inspeções visuais no interior das edificações foram classificadas como um dos principais métodos para se avaliar os ajustes dos EIS (O'BRIEN; KAPSIS; ATHIENITIS, 2013). De maneira geral, os autores afirmam que os estudos baseados em walkthroughs são menores que os demais, tanto em termos de número de EIS avaliados quanto em relação à duração (O'BRIEN; KAPSIS; ATHIENITIS, 2013). Por outro lado, esse método permite que os observadores também conversem com os usuários, facilitando a compreensão sobre motivos específicos para os ajustes, bem como os fatores que influenciam na porcentagem de obstrução das janelas. Visando reduzir os custos dos experimentos e considerando que os EIS não são ajustados com tanta frequência quanto outros sistemas das edificações, a literatura sugere que essas avaliações sejam conduzidas em intervalos de tempo significativos (pelo menos uma semana entre uma avaliação e a próxima). Ressalta-se, entretanto, que esses intervalos de tempo podem dificultar a determinação exata dos fatores que impactaram nos ajustes dos elementos.

Avaliações pós-ocupação (APO) podem reportar resultados importantes em relação à operação de EIS em edificações (DAY, 2012). As avaliações pós-ocupação podem incluir aplicação de questionários aos usuários para entender quão satisfeitos eles estão com o desempenho dos sistemas e da edificação, bem como realizar registros fotográficos e entrevistas. Além disso, Nezamdoost, Wymelenberg e Mahic (2018) recomendam a realização de avaliações pós-ocupação, especificamente para avaliar o uso dos EIS, visando criar algoritmos mais confiáveis para representar os ajustes desses sistemas. Os autores expõem que muitos algoritmos apresentados na literatura funcionam tão bem quanto, senão melhor, que controles automatizados; portanto, estudos de observação podem apresentar fatores subjetivos relacionados a essas interações e melhorar as práticas na área a fim de tornar os algoritmos mais precisos.

\section{Fotografias}

O uso de fotografias permite avaliar grande número de janelas em relação à operação dos EIS, principalmente se as fotos forem da fachada, possibilitando avaliar diversas janelas em um único registro. Por esse motivo, O’Brien, Kapsis e Athienitis (2013) afirmam que estudos baseados em fotografia são os que apresentam maiores números de registros em comparação aos baseados em sensores ou walkthroughs. Ressalta-se que para obter resultados válidos para as avaliações, as fotografias das fachadas devem ser tiradas com câmeras de alta resolução para permitir a avaliação de todas as janelas, como realizado por Nezamdoost et al. (2018), uma vez que a baixa resolução das fotos pode dificultar a interpretação das imagens. A utilização de câmeras também possibilita filmar os ambientes para avaliar de maneira contínua os ajustes dos sistemas. Entretanto, como exposto por Yao (2014), as gravações dificultam a análise dos dados e tornam os experimentos mais caros quando comparados aos baseados em fotografia. Além disso, em algumas edificações, os EIS sofrem poucas alterações ao longo de dias, e até semanas, o que torna inviável a utilização de gravações para avaliar os ajustes. De maneira geral, a utilização de fotografias permite grande adaptabilidade à realidade de cada local onde serão realizados os experimentos, e a literatura apresenta variações em relação aos métodos empregados, verificando-se o uso de:

(a) diferentes abordagens: fotos do interior dos ambientes (ALAM; SHARI, 2019) ou das fachadas (DAY, 2012; GUNAY et al., 2017; MAHDAVI, 2009; NEZAMDOOST et al., 2018);

(b) diferentes intervalos de tempo: a cada trinta minutos (GUNAY et al., 2017), uma vez por hora (YAO, 2014), ou a cada duas horas (DAY, 2012; NEZAMDOOST et al., 2018);

(c) diferentes durações dos monitoramentos: duas semanas (DAY, 2012); dezesseis dias (NEZAMDOOST et al., 2018); 21 dias em dois meses do ano (ALAM; SHARI, 2019); e

(d) combinação com outros métodos: e.g., com aplicação de questionários para avaliar variáveis subjetivas (DAY, 2012; ALAM; SHARI, 2019; ZHANG; BARRETT, 2012), com dados de monitoramento de sensores integrados a sistemas de automação predial (GILANI; O’BRIEN; CARRIZO, 2017; GUNAY et al., 2017), ou com variáveis ambientais externas (MAHDAVI, 2009; NEZAMDOOST et al., 2018).

Geralmente, as fotografias são analisadas manualmente e as informações inseridas em um banco de dados. De acordo com os objetivos da pesquisa, maiores níveis de detalhamento podem ser considerados: a 
porcentagem de obstrução, por exemplo, pode ser avaliada e incluída em modelos preditivos de ajustes de EIS. Responsáveis pelos estudos de campo podem optar por avaliar os ajustes dos EIS em relação à porcentagem de área envidraçada que está encoberta, bem como os ângulos que as aletas das persianas estão formando, e se estão inclinadas para cima ou para baixo. Como mostrado por O’Brien, Kapsis e Athienitis (2013), essas variações impactam as dinâmicas de aproveitamento de iluminação natural. Entretanto, é necessário delimitar quão amplo o estudo será, e avaliar a necessidade de maiores níveis de detalhando tendo em vista que estes podem aumentar o grau de complexidade e custo das avaliações.

\section{Instalação de sensores}

Apesar de mais caros e trabalhosos em relação a observações ou registros fotográficos pontuais, monitoramentos com instalação de sensores são adequados para avaliar ajustes de EIS. Haldi e Robinson (2010) utilizaram os dados de uma longa campanha de monitoramento (de janeiro de 2004 a abril de 2009) para analisar os ajustes dos EIS, tanto em relação à abertura e ao fechamento quanto em relação às porcentagens de obstrução das janelas. Por ser um dos primeiros estudos de longa duração realizado na área, os resultados obtidos são empregados até hoje em outros estudos, tanto como inspiração para a modelagem do comportamento dos usuários quanto para a utilização dos modelos criados pelos autores a fim de realizar comparações. A instalação de sensores pode compreender o monitoramento dos próprios elementos de sombreamento (e.g., sensor de deslocamento em uma persiana para avaliar os ajustes) e/ou de variáveis ambientais no interior (e.g., temperatura do ar, iluminância, radiação solar, etc.) ou no exterior das edificações (e.g., utilização de estações climáticas). Uma prática comum nessas avaliações é combinar os monitoramentos de ajustes de EIS aos de variáveis ambientais a fim de encontrar fatores que impactam no ajuste dos sistemas.

Nos estudos de Stazi, Napsi e D'Orazio (2017), os autores listaram os principais fatores apresentados como impactantes nos ajustes de EIS, sendo: iluminância, radiação solar, ofuscamento e temperaturas internas e externas. Desta forma, avaliações futuras podem se basear em estudos já realizados para determinar quais variáveis precisam ser monitoradas em campo a fim de otimizar tanto a coleta quanto a análise dos dados. Além disso, em relação aos equipamentos utilizados, D’Oca et al. (2019b) afirmam que as limitações de armazenamento de dados e de duração das baterias podem impactar negativamente as avaliações. É importante que os responsáveis determinem intervalos para o registro de dados que reduzam a necessidade de visitas aos escritórios, e que, mesmo assim, possibilitem a criação de modelos que representem os ajustes de maneira adequada. Por fim, apesar de mais trabalhoso em relação à instalação de sensores nos ambientes monitorados, O’Brien, Kapsis e Athienitis (2013) apresentaram a possibilidade de combinar walkthroughs a medições com equipamentos portáteis, incluindo registros fotográficos. Tendo em vista que a literatura associa, principalmente, fatores relacionados às dinâmicas que impactam conforto visual e térmico dos ocupantes aos ajustes dos EIS, os autores sugerem a utilização de sensores para essas variáveis em avaliações pontuais em campo.

Além da instalação de equipamentos providos de sensores a fim de avaliar pontualmente o comportamento dos usuários (sensores de contato para avaliar abertura e fechamento de janelas, sensores de deslocamento para avaliar ajustes em persianas do tipo rolô, sensores de presença, etc.) a literatura também apresenta a utilização de sensores já acoplados ao prédio (como os dos sistemas automatizados) para a coleta de dados ambientais e de ajustes dos EIS (GILANI; O’BRIEN; CARRIZO, 2017; GUNAY et al., 2017). De maneira geral, esse tipo de abordagem pode melhorar as dinâmicas dos sistemas, uma vez que ao se avaliar com precisão as preferências dos ocupantes, os modelos de automação podem ser melhorados para que maiores níveis de satisfação sejam atingidos.

\section{Estudos em ambientes imersivos e/ou controlados}

Recentemente, Bavaresco et al. (2019a) apresentaram uma revisão de literatura sobre diversas inovações tecnológicas que podem ser empregadas para avaliar o comportamento dos usuários em edificações. Dentre as práticas apresentadas, os autores mostraram a viabilidade de se empregar ambientes imersivos, uma vez que eles permitem realizar experimentos curtos ou replicar experimentos que custariam muito se realizados em campo. Considerando-se estudos de comportamento de usuário especificamente em relação aos ajustes dos EIS, a literatura confirma essa possibilidade (CARNEIRO; ARYAL; BECERIK-GERBER, 2019; HEYDARIAN et al., 2015). Nesse sentido, pesquisadores podem comparar diferentes condições de iluminação e demais variáveis ambientais que impactam os ajustes dos EIS ao proporcionar o controle desse sistema nos ambientes de estudo. Ambientes imersivos também foram utilizados para avaliar a relação entre a combinação de desconforto visual e térmico aos ajustes dos sistemas das edificações (OZCELIK; 
BECERIK-GERBER; CHUGH, 2019). Os autores concluíram que quando os usuários são submetidos a situações desconfortáveis tanto em relação aos estímulos visuais quanto às sensações térmicas, a primeira ação realizada no ambiente é o ajuste dos EIS, evidenciando a clara relação entre diferentes aspectos ambientais nas tomadas de decisão dos usuários.

Câmaras climáticas também são úteis para avaliar comportamento de usuário, principalmente quando o ambiente é semi-controlado e permite que os participantes ajustem os sistemas (WAGNER; O'BRIEN; DONG, 2017). Ao avaliar o efeito da ocupação nas sensações térmicas e comportamento de usuários, Schweiker e Wagner (2016) concluíram que o aumento do número de pessoas em um ambiente de escritório tende a reduzir os ajustes de sistemas como as persianas. Em partes, esse fato deve-se à redução do controle percebido pelos usuários de ambientes compartilhados em comparação a ambientes individuais, embora mais pesquisa seja necessária nessa área. Ressalta-se que a utilização de câmaras climáticas nesses estudos pode facilitar a comparação de diferentes limites de variáveis ambientais internas nos ajustes dos sistemas. Por exemplo, a partir de um estudo de campo que constata que a temperatura interna é o fator mais impactante nos ajustes de EIS, câmaras climáticas podem ser utilizadas para testar com maior precisão quais são os limites aceitáveis para esse parâmetro até que o sistema seja ajustado.

\section{Aplicação de questionários}

Além de avaliações objetivas por meio de monitoramentos ou registros fotográficos, a operação de elementos internos de sombreamento também pode ser avaliada subjetivamente por meio de questionários (HAZBOUN, 2018; ALAM; SHARI, 2019; SADEGHI et al., 2017; ZHANG; BARRETT, 2012). Considerando-se aspectos subjetivos relacionados ao comportamento dos usuários - como os construtos da Teoria do Comportamento Planejado - a literatura evidencia a possibilidade de avaliar a influência das dinâmicas sociais de compartilhamento dos sistemas na intenção que os usuários têm de ajustá-los (D’OCA et al., 2017). Nesse sentido, resultados de questionários podem apresentar importantes conclusões em relação à variação observada em diferentes contextos climáticos e culturais (D'OCA et al., 2018). Comparando-se diferentes edificações avaliadas por meio do mesmo questionário, D'Oca et al. (2019a) mostraram que usuários de smart buildings têm maior conhecimento sobre os ajustes dos EIS. Isso evidencia que aplicações de questionários podem apresentar conhecimentos subjetivos importantes para o setor de edificações.

De maneira objetiva, avaliações baseadas em questionários podem obter dos ocupantes os principais momentos de ajustes dos EIS, bem como os principais motivos para as interações. Essas informações permitem elaborar padrões de comportamento ao longo do tempo, além de favorecer a criação de padrões baseados em variáveis ambientais (BAVARESCO; GHISI, 2018). Um problema quanto a esse método é a inexistência de medições em campo, que dificulta a determinação dos limites aceitáveis para os usuários. Entretanto, em uma visão mais global, algoritmos criados em outros estudos podem ser aplicados em simulações computacionais para avaliar as probabilidades de fechamento baseadas em variáveis ambientais.

Questionários em formato similar aos de diário (Time Use Survey) também foram empregados para avaliar o status dos EIS por Jia et al. (2019). Nessa avaliação, solicitou-se aos participantes que registrassem o status dos sistemas em intervalos de quinze minutos. Considerando-se a utilização de sensores para avaliar as variáveis ambientais internas, os dados de status dos sistemas podem representar informações importantes para a elaboração de modelos de comportamento tanto baseados em tempo quanto baseados em variáveis ambientais. De maneira similar, porém menos invasiva, solicitou-se aos usuários que anotassem os ajustes dos sistemas apenas nos momentos em que abrissem ou fechassem as persianas, e não em intervalos de tempo pré-estabelecidos (KATSANOU; ALEXIADIS; LABRIDIS, 2019). Além disso, questionários podem ser empregados para avaliar fatores subjetivos relacionados aos ajustes dos EIS, como realizado por Schweiker, Hawighorst e Wagner (2016). Nesse estudo, os autores avaliaram os traços de personalidade dos participantes para avaliar se essas características impactam no modo de ajustar os sistemas de uma edificação.

\section{Comparação entre os métodos de monitoramento}

Por não haver normas para realizar estudos sobre comportamento de usuário, diversos métodos são apresentados na literatura como viáveis para esses estudos. Portanto, é de responsabilidade de quem realiza as avaliações escolher tanto o método quanto as especificidades dos estudos de campo. Para facilitar a comparação entre as vantagens e desvantagens de cada método, determinadas a partir da revisão de literatura, o Quadro 1 sintetiza os cinco métodos revisados. Espera-se que a apresentação dessas 
comparações facilite o planejamento de futuros estudos nessa área. Por fim, ressalta-se a importância de combinar diferentes métodos, a fim de permitir a triangulação das informações obtidas para confiabilidade dos resultados (DAY, 2012).

Quadro 1 - Comparação entre os métodos apresentados para monitorar os ajustes dos elementos internos de sombreamento

\begin{tabular}{|c|c|c|}
\hline Método & Vantagens & Desvantagens \\
\hline $\begin{array}{l}\text { Avaliações } \\
\text { em campo - } \\
\text { Walkthroughs }\end{array}$ & $\begin{array}{l}\text { - Permitem avaliar com mais clareza os ângulos } \\
\text { das aletas de persianas, bem como os } \\
\text { percentuais de obstrução; } \\
\text { - Permitem interação como os usuários para } \\
\text { entender porque determinado elemento foi (ou } \\
\text { não) ajustado e o que influencia o } \\
\text { posicionamento. }\end{array}$ & $\begin{array}{l}\text { - Demandam bastante tempo e pode } \\
\text { ser necessário envolver uma grande } \\
\text { equipe; } \\
\text { - Avaliações em diferentes cidades } \\
\text { são dificultadas pela necessidade de } \\
\text { comparecimento in loco; } \\
\text { - Usuários podem se sentir } \\
\text { constrangidos com a presença de } \\
\text { observadores nos ambientes. }\end{array}$ \\
\hline Fotografias & $\begin{array}{l}\text { - Podem ser fotos das fachadas, tornando as } \\
\text { avaliações menos invasivas e facilitando a } \\
\text { avaliação de um grande número de janelas; } \\
\text { - Permitem a avaliação dos percentuais de } \\
\text { obstrução das janelas; } \\
\text { - Se as câmeras forem instaladas no local, reduz } \\
\text { a necessidade de presença dos pesquisadores. }\end{array}$ & $\begin{array}{l}\text { - Não permitem avaliar as condições } \\
\text { internas, como variáveis ambientais; } \\
\text { - Difícil avaliação dos ângulos das } \\
\text { aletas de persianas, principalmente } \\
\text { quando tiradas do exterior; } \\
\text { - Se tiradas pelos pesquisadores, } \\
\text { necessitam comparecimento in loco. }\end{array}$ \\
\hline $\begin{array}{l}\text { Instalação de } \\
\text { sensores }\end{array}$ & $\begin{array}{l}\text { - Caso sejam utilizados sensores portáteis, } \\
\text { pesquisadores podem realizar monitoramentos } \\
\text { empregando baixa quantidade de equipamentos } \\
\text { a fim de reduzir os custos da pesquisa; } \\
\text { - Permite estabelecer limites mais consistentes } \\
\text { para os ajustes dos EIS, favorecendo a } \\
\text { modelagem do comportamento dos usuários } \\
\text { para simulações computacionais; } \\
\text { - Em prédios com sistemas automatizados, os } \\
\text { próprios sensores podem fornecer dados para os } \\
\text { estudos. }\end{array}$ & $\begin{array}{l}\text { - O custo pode ser elevado em } \\
\text { relação aos outros métodos, } \\
\text { principalmente se o número de } \\
\text { ambientes monitorados for grande; } \\
\text { - Dependendo dos equipamentos, } \\
\text { problemas como baixa capacidade } \\
\text { de armazenamento ou pouca duração } \\
\text { das baterias pode afetar } \\
\text { negativamente a coleta de dados; } \\
\text { - Se não escolhidos com critério, os } \\
\text { dados monitorados podem ser pouco } \\
\text { explicativos para os ajustes dos EIS. }\end{array}$ \\
\hline $\begin{array}{l}\text { Estudos em } \\
\text { ambientes } \\
\text { imersivos } \\
\text { e/ou } \\
\text { controlados }\end{array}$ & $\begin{array}{l}\text { - Permitem realizar experimentos curtos ou } \\
\text { replicar experimentos que custariam muito se } \\
\text { realizados em ambientes reais; } \\
\text { - Em ambientes controlados, pesquisadores } \\
\text { podem testar a combinação de diferentes limites } \\
\text { de parâmetros ambientais nos ajustes dos EIS. }\end{array}$ & $\begin{array}{l}\text { - Os estudos demandam maior } \\
\text { investimento em relação aos demais } \\
\text { métodos; } \\
\text { - Em ambientes imersivos, } \\
\text { participantes podem se sentir mal } \\
\text { por não estarem acostumados à } \\
\text { tecnologia; } \\
\text { - Por estarem sendo observados, } \\
\text { usuários podem se comportar de } \\
\text { maneira atípica. }\end{array}$ \\
\hline $\begin{array}{l}\text { Aplicação de } \\
\text { questionários }\end{array}$ & $\begin{array}{l}\text { - Baixo custo; } \\
\text { - O anonimato dos respondentes pode ser } \\
\text { garantido; } \\
\text { - O mesmo questionário pode ser aplicado em } \\
\text { diferentes locais e edificações, a fim de avaliar } \\
\text { a influência de fatores climáticos e culturais nos } \\
\text { ajustes dos EIS; } \\
\text { - Possibilita a avaliação de fatores subjetivos } \\
\text { relacionados aos ajustes de EIS; } \\
\text { - As avaliações em campo são menos invasivas, } \\
\text { principalmente quando os questionários são } \\
\text { aplicados em plataformas online. }\end{array}$ & $\begin{array}{l}\text { - Usuários podem responder de } \\
\text { acordo com o que eles imaginam } \\
\text { que seja aceitável, e não } \\
\text { necessariamente como eles se } \\
\text { comportam; } \\
\text { - Caso as taxas de resposta sejam } \\
\text { baixas, os resultados dificilmente } \\
\text { representarão a população; } \\
\text { - Se aplicados de forma impressa, } \\
\text { exigem presença dos responsáveis in } \\
\text { loco e as análises das respostas } \\
\text { podem ser dificultadas. }\end{array}$ \\
\hline
\end{tabular}




\section{Modelagem de padrões de comportamento}

A modelagem de padrões de comportamento de usuário para inclusão em simulações computacionais depende de diversos fatores, como o tipo dos dados levantados, a granularidade dos dados, o tipo da edificação, e até o comportamento específico em que se deseja ter conhecimento. Em alguns casos, como exposto por Gilani, O’Brien e Gunay (2018), schedules padrão para o controle de EIS assumem que eles são mantidos sempre abertos (em outras palavras, são inexistentes), tanto considerando-se o código nacional canadense quanto práticas no setor da construção civil em outros países. Portanto, é importante que mais estudos sejam realizados nessa área a fim de modelar com mais precisão os ajustes dos EIS, viabilizando a criação de modelos base para serem incluídos em edificações de referência, ao invés da desconsideração desses sistemas. Nesse sentido, a literatura confirma que a consideração de modelos simples, porém coerentes, pode gerar melhores resultados em comparação a modelos muito complexos que superestimem a influência dos usuários (GAETANI; HOES; HENSEN, 2016).

D’Oca et al. (2019b) apresentaram uma revisão de literatura sobre as abordagens de modelagem mais utilizadas na área de comportamento de usuário. Apesar do escopo amplo do trabalho, sistemas específicos como os sombreamentos internos também foram considerados na revisão. De maneira geral, os autores concluíram que as abordagens mais comuns englobam os modelos de comportamento adaptativo, modelos de comportamento não adaptativo e modelos de ocupação. Considerando-se os EIS, os modelos adaptativos geralmente consideram variáveis ambientais como motivadores de ajustes nas edificações (e.g., fechamento dos EIS quando a radiação solar no plano de trabalho atinge um limite estabelecido). Os modelos de comportamento não adaptativos podem incluir schedules baseadas no tempo, tanto considerando-se modelagem estática quanto cálculos de probabilidade baseados em fatores temporais (e.g., abertura dos EIS na chegada ao escritório).

Em relação aos modelos já apresentados, destaca-se o estudo de Haldi e Robinson (2010), que devido ao extenso período de monitoramento realizado permitiu criar modelos mais fáceis de serem validados. Os autores empregaram dados de seis anos de levantamento em campo e criaram um modelo estocástico de Markov para representar os ajustes dos EIS. O modelo foi empregado em outros estudos comparativos em relação às técnicas de modelagem, como os de Gilani et al. (2016) e Gunay, O’Brien e Beausoleil-Morrison (2016). De maneira similar, a literatura também apresenta o modelo criado por Reinhart (2004), que originou o algoritmo Lightswitch-2002 e pode ser aplicado em simulações com o plug-in DIVA no programa Rhinoceros. Esse modelo também foi empregado em outros estudos, como os de Gunay, O'Brien e Beausoleil-Morrison (2016) e Bavaresco e Ghisi (2018). Recentemente, o algoritmo Blindswitch-2018 foi apresentado como uma alternativa ao Lightswitch-2002, considerando-se os avanços nos estudos de ajustes de EIS (NEZAMDOOST et al., 2018). A principal mudança é a inclusão da característica pouco ativa dos usuários em relação aos ajustes dos EIS, uma vez que os autores analisaram mais de 90.000 registros de posição de EIS e concluíram que a maioria deles tende a ser pouco ajustada ao longo da operação das edificações. Diferentes algoritmos (Lightswitch e o Blindswtich, e LM-83) foram comparados com modelos automatizados por Nezamdoost, Wymelenberg e Mahic (2018). Os autores concluíram que, apesar dos avanços na área, os algoritmos criados para operação dos EIS ainda são similares a controles automatizados, e não representam com total precisão a maneira com que os usuários ajustam os sistemas das edificações. Por fim, modelos já apresentados na literatura também foram sintetizados por Wang, Hong e Jia (2019), que elaboraram o pacote "Buildings.Occupants" para considerar comportamento de usuário no programa Modelica. Em relação aos ajustes de EIS, os autores utilizaram seis modelos apresentados anteriormente na literatura, com dados obtidos em quatro países: Japão, Estados Unidos, Suíça e Reino Unido.

Nesta seção são apresentados e discutidos brevemente os principais modelos encontrados na literatura para representar os ajustes dos EIS: baseados em técnicas de aprendizado de máquina, baseados em agentes, e dependentes de regras.

\section{Modelos baseados em técnicas de aprendizagem de máquina e mineração de dados}

Em relação às abordagens baseadas em técnicas de aprendizagem de máquina, destaca-se a utilização de modelos estocásticos de Markov. Balvedi, Ghisi e Lamberts (2018) destacam que os modelos estocásticos são criados a partir do cálculo das probabilidades de mudança de estado de um determinado sistema: a probabilidade de uma persiana que está fechada ser aberta por um usuário, por exemplo. Um exemplo da utilização dessa abordagem pode ser encontrado no estudo de Haldi e Robinson (2010) - destacado no início desta seção. Os autores empregaram processos de Markov com base no status inicial dos EIS e nos níveis de 
iluminância internos e externos para calcular as probabilidades de ajustes nos sistemas ao longo do período de ocupação dos ambientes. De maneira similar, destaca-se o algoritmo Lightswitch-2002 que foi criado a partir do cálculo das probabilidades de ajustes nos EIS por Reinhart (2004). O algoritmo foi incorporado no plug-in DIVA para o programa computacional Rhinoceros, permitindo ampla utilização por pesquisadores e profissionais de diferentes locais.

A utilização de técnicas distintas para modelar a abertura e o fechamento dos EIS também foi encontrada na literatura. Gunay et al. (2017) empregaram função de sobrevivência como método de estimativa das aberturas dos EIS e regressão logística de Markov para estimar o fechamento. Avaliações diferenciadas podem ser válidas pela dependência de diferentes fatores em relação aos ajustes dos EIS: as aberturas tendem a estar mais condicionadas ao tempo (momento de chegada ao ambiente), enquanto os fechamentos tendem a estar mais condicionados a variáveis ambientais (radiação solar, temperatura, etc.). De maneira similar, técnicas diferentes também podem ser utilizadas para estabelecer os padrões de ajustes dos EIS e, posteriormente, estimar o percentual de obstrução causado pelos ajustes - abordagem empregada no estudo de Haldi e Robinson (2010).

Além de modelos estocásticos, a literatura também apresenta a utilização de redes neurais artificiais para predizer ajustes de EIS em edificações. Esses modelos podem adicionar detalhes às predições ao se incluir a avaliação de condições internas dos ambientes considerando o comportamento dos usuários (KATSANOU; ALEXIADIS; LABRIDIS, 2019). De maneira similar, modelos de aprendizagem de máquina baseados no teorema de Bayes também foram utilizados para classificar tanto os ajustes dos EIS (abertura/fechamento) quanto os percentuais de obstrução das janelas resultantes após os ajustes (SADEGHI et al., 2017). Essa abordagem facilita a criação de redes Bayesianas para calcular as probabilidades de ajustes em sistemas de edificações. Por fim, modelos logísticos também são apresentados na literatura como fontes valiosas de informações a respeito dos ajustes dos EIS (ZHANG; BARRETT, 2012). Ao se avaliar as probabilidades de ajustes de acordo com diferentes níveis de variáveis ambientais, essas informações também são úteis para aumentar o conhecimento dos profissionais da área quanto ao uso dos EIS.

\section{Modelos baseados em agentes}

Gaetani, Hoes e Hensen (2016) apresentaram a modelagem baseada em agentes (agent-based modelling $A B M$ ) como uma técnica mais complexa, que tenta predizer o comportamento de indivíduos isoladamente. Por modelar os usuários individualmente e também suas interações com os demais ocupantes e com os sistemas das edificações, essa técnica requer maior nível de detalhamento e, muitas vezes, as informações necessárias não estão disponíveis. Apesar do ponto negativo em exigir maior detalhamento e complexidade, a modelagem baseada em agentes tem sido apresentada recentemente como uma técnica promissora para os estudos de comportamento de usuário. A vantagem dessa técnica é avaliar os ajustes com grande precisão, adicionando aspectos subjetivos de cada indivíduo envolvido no controle das edificações. A literatura evidencia a possibilidade de se combinar diversos critérios para determinar os níveis de desconforto dos agentes (usuários) e determinar as probabilidades de ajustes dos sistemas das edificações.

Em relação à modelagem baseada em agentes para a representação de ajustes de EIS, uma contribuição recente que pode aprimorar as práticas foi apresentada por Schweiker, Hawighorst e Wagner (2016). Ao incluir a avaliação dos traços de personalidade dos usuários e o impacto dessas características no modo com que eles ajustam os sistemas das edificações, os modelos baseados em agentes podem considerar fatores mais individualizados para a representação de cada um dos agentes envolvidos nas simulações. No estudo, os autores encontraram relações entre alguns traços de personalidade e os ajustes dos EIS: maiores níveis de neuroticismo reduzem a probabilidade dos usuários fecharem os EIS, enquanto maiores níveis de extroversão aumentam a probabilidade dos usuários fecharem os EIS. Além da modelagem visando simulação computacional, abordagens com maiores níveis de detalhamento avançam os estudos e a elaboração de design e controle centrados nos usuários, tanto em relação às edificações quanto aos sistemas em si. Quanto mais informações forem obtidas sobre esses aspectos, mais os pesquisadores e responsáveis por desenvolvimento de novas tecnologias poderão avançar em suas práticas profissionais.

\section{Modelos dependentes de regras (tempo e/ou variáveis ambientais)}

De maneira geral, esses modelos tendem a ser mais complexos que as schedules fixas, mas representam abordagens mais simplificadas em relação aos modelos baseados em agentes ou em cálculos probabilísticos. Em relação às schedules fixas, ressalta-se que, apesar de amplamente utilizadas para representar ocupação 
ou uso de alguns equipamentos em escritórios, essa abordagem simplificada não costuma ser utilizada para representar ajustes dos EIS.

Os modelos dependentes de regras (ou dados) são determinísticos; isto é, não apresentam caráter probabilístico, o que confere alto grau de previsibilidade: sempre que determinado limite for atingido, o ajuste relacionado a ele será executado. Regras baseadas em tempo (momentos do dia, por exemplo) são apresentadas na literatura como uma solução para representar os ajustes de EIS em simulações computacionais. A regra baseada em tempo mais comumente empregada está relacionada à abertura dos EIS, que tende a ocorrer no momento de chegada ao escritório, tanto no início da manhã quanto depois do almoço (BAVARESCO; GHISI, 2018; JAKUBIEC; REINHART, 2011). O fechamento, entretanto, não é frequentemente modelado em função do tempo, mas sim de variáveis ambientais, que podem ser calculadas durante as simulações computacionais. Nesse sentido, limites como $50 \mathrm{~W} / \mathrm{m}^{2}$ de radiação solar no plano de trabalho e temperatura interna igual a $24^{\circ} \mathrm{C}$ foram utilizados como motivadores para o fechamento dos EIS (BAVARESCO et al., 2019b; BAVARESCO; GHISI, 2018). Modelos dependentes de tempo também foram utilizados na literatura considerando-se usuários isolados, isto é, cada usuário teve seu comportamento avaliado em ambientes imersivos e, então, o padrão resultante foi inserido em simulações computacionais para compará-lo com um modelo de referência (CARNEIRO; ARYAL; BECERIK-GERBER, 2019). Esta abordagem pode ser útil para testar o desempenho de novos materiais, por exemplo, considerando-se o impacto do comportamento dos usuários nas simulações.

A literatura também apresentou modelos de controle baseados em variáveis ambientais (condição do céu) combinados a fatores da edificação (ocupação e status de condicionamento) (ZHANG; LAM, 2011). Esses algoritmos foram criados com o intuito de aumentar o ganho de calor externo e minimizar a perda de calor interno quando o ambiente está sendo aquecido, e manter a situação oposta quando o ambiente está sendo resfriado. Desta forma, algumas estratégias para melhorar o desempenho da edificação podem ser traçadas:

(e) quando resfriamento é necessário, deve-se manter os EIS abertos durante a noite independentemente da ocupação; ou

(f) quando aquecimento é necessário, deve-se manter os EIS abertos se o dia estiver ensolarado independentemente da ocupação.

Apesar de completos em relação às dinâmicas de física da edificação, por otimizar o desempenho termoenergético, esses modelos de controle ideais são dificilmente implementados em situações reais.

Por fim, Gilani, O’Brien e Gunay (2018) concluíram que a precisão dos modelos baseados em regras pode estar condicionada à dimensão das edificações. Ou seja, ao se avaliar uma sala específica, é necessário representar o comportamento dos usuários de maneira muito verossímil ao real; porém, quando a dimensão das edificações aumenta, modelagens mais simplificadas podem ser suficientes por representarem a média de diversos ambientes. Esta é uma conclusão importante que pode apoiar o uso de modelos baseados em regras para a consideração dos ajustes dos EIS em simulações de edificações referência. Deve-se, portanto, determinar os principais fatores que motivam os ajustes dos EIS em diferentes locais para facilitar a elaboração e aplicação desses modelos.

\section{Aplicação em simulação computacional}

Alguns estudos não aplicaram simulação computacional de desempenho de edificações, pois focaram na criação dos modelos de comportamento em si. Entretanto, muitos dos modelos criados estão aptos para serem empregados em simulações computacionais em programas amplamente utilizados. Esse é o caso do estudo de Jia et al. (2019), que concluíram que o modelo baseado em agentes está validado em relação ao tempo e apto para ser incluído em simulações no EnergyPlus. De modo similar, os estudos de Reinhart (2004) e Nezamdoost et al. (2018) apresentaram os algoritmos Lightswitch e Blindswitch, respectivamente, para serem integrados em simulações computacionais, tanto de desempenho termoenergético quanto de dinâmicas de iluminação natural em edificações.

Avaliando-se os estudos que empregaram simulação, o programa computacional mais utilizado nessa área é o EnergyPlus. Esse programa permite a utilização do recurso Energy Management System (EMS) nas simulações que consideram os ajustes dos EIS, a fim de inserir controles avançados nas simulações (GILANI et al., 2016; GUNAY; O'BRIEN; BEAUSOLEIL-MORRISON, 2016). A possibilidade de inserir diferentes controles favorece a combinação de fatores associados aos ajustes dos EIS a fim de minimizar incongruências como: um controle baseado na temperatura interna não fechar os EIS quando os usuários estão sujeitos a desconforto visual, ou um controle baseado em radiação solar abrir os EIS quando os 
usuários os manteriam fechados devido à temperatura interna elevada. Entretanto, a literatura também evidencia a deficiência do EnergyPlus nos cálculos de iluminação natural e mostra que o algoritmo do Daysim/Radiance é mais adequado para esse propósito (RAMOS; GHISI, 2010). Como o uso de elementos internos de sombreamento impacta tanto as dinâmicas de trocas de calor (representadas com precisão pelo EnergyPlus) quanto as dinâmicas de iluminação natural (representadas com precisão pelo Daysim/Radiance), é notável a combinação desses programas computacionais na literatura (BAVARESCO; GHISI, 2018; FERNANDES et al., 2018; GILANI et al., 2016; JAKUBIEC; REINHART, 2011; NEZAMDOOST; WYMELENBERG; MAHIC, 2018).

Ressalta-se que os ajustes nos EIS impactam nas dinâmicas de aproveitamento de iluminação natural, colocando os usuários como os responsáveis por administrar o balanço entre aproveitamento de iluminação natural e uso de iluminação artificial. Portanto, com o intuito de avaliar o desempenho de uma edificação considerando-se aspectos de seu desempenho lumínico é necessário compreender se os programas computacionais empregados são adequados. Nesse sentido, a Agência Internacional de Energia, por meio da IEA SHC Task 61 "Integrated solutions for daylight and electric lighting" visa desenvolver estratégias de integração entre iluminação natural e artificial para obter sistemas de iluminação eficientes oferecendo as melhores condições de iluminação para os ocupantes. Confirmando a relação entre comportamento de usuários e a elaboração de tecnologias centradas nessas necessidades, a Subtask $A$ "User perspective and requirements" visa compreender as preferências dos usuários, realizar estudos de caso e representar o comportamento dos usuários. De maneira geral, a melhor representação dos padrões de comportamento impactará positivamente as práticas de simulação computacional por profissionais do setor de edificações, uma vez que os produtos finais do grupo de pesquisa visam integrar os padrões de comportamento aos programas de simulação computacional utilizados.

A estratégia de combinar diferentes programas computacionais para resolver problemas específicos é apresentada na literatura como co-simulação. Quanto aos ajustes de EIS, métodos de co-simulação podem ser aplicados para elaborar os modelos de comportamento e incluí-los nas simulações termoenergéticas e lumínicas. Nesse sentido, Yao (2014) apresentou o BCVTB (Building Controls Virtual Test Bed) como um ambiente de simulação que permite incorporar modelos estocásticos criados para representar o comportamento de usuários em programas reconhecidos como o EnergyPlus. Nesse sentido, as matrizes de transição dos modelos de Markov podem ser modeladas no BCVTB e incluídas nas simulações de desempenho termoenergético e lumínico. A utilização do BCVTB combinado ao EnergyPlus também foi apresentada como uma estratégia para a aplicação de modelos baseados em agentes (LEE; MALKAWI, 2014). Ressalta-se que quando diferentes programas são utilizados, é necessário definir e compatibilizar os modelos nos ambientes de simulação empregados. Ainda em relação às simulações baseadas em agentes, Chen, Hong e Luo (2018) apresentaram o Occupancy Simulator: uma ferramenta que considera cada ocupante e ambiente como agentes empregando modelos estocásticos desenvolvidos anteriormente. Ou seja, o simulador permite criar perfis de comportamento de usuário com base em dados já apresentados anteriormente para serem inseridos em simulações computacionais.

\section{Aplicação em sistemas de automação predial}

A literatura confirma a necessidade de considerar os ajustes de EIS realizados manualmente quando um sistema automatizado é proposto. Nesse sentido, recomenda-se que os ajustes manuais sejam considerados pelo menos como baseline nas simulações, ao invés de comparar os sistemas automatizados propostos com cenários sem a consideração de EIS (NEZAMDOOST; WYMELENBERG; MAHIC, 2018). Desta forma, ao se aprofundar o conhecimento sobre as preferências dos usuários em relação aos ajustes manuais dos EIS, sistemas automatizados centrados nos usuários podem ser propostos como alternativa para aumentar os níveis de aceitação dessa tecnologia.

Além da possibilidade de utilizar os modelos criados para melhorar os resultados de sistemas automatizados, os próprios sistemas automatizados também favorecem a criação de modelos de comportamento (GUNAY et $a l .$, 2017). Nesse sentido, é importante enfatizar a inter-relação entre os avanços na compreensão sobre as preferências dos usuários de edificações e a melhoria dos sistemas de automação predial, pelo ponto de vista de aceitação por parte dos usuários. Quanto à aceitação, Bavaresco et al. (2019a) apresentaram a viabilidade de considerar feedback dos usuários quanto ao funcionamento dos sistemas. Nesse sentido, ao se permitir ajustes em sistemas automatizados, o modelo passa a receber feedback sobre as preferências dos usuários, facilitando a obtenção de sistemas que operam de acordo com as necessidades de quem o ajusta. Esse aspecto também é válido para sistemas automatizados de controle de EIS, e estudos por meio de simulações computacionais mostraram que a inserção de sistemas automatizados que aprendem a partir do 
comportamento adaptativo dos usuários pode reduzir significativamente o consumo energético de edificações (GUNAY et al., 2014).

A viabilidade de se avaliar o comportamento dos usuários em relação à proposição de sistemas automatizados de controle de EIS pode ser compreendida no ciclo apresentado na Figura 1. A principal sugestão desta revisão é que a busca por padrões de comportamento de usuário não acabe após a proposição de sistemas automatizados; pelo contrário, os próprios sistemas automatizados podem ser ajustados às preferências dos ocupantes a fim de aumentar os níveis de conforto nos escritórios. Ressalta-se que os usuários podem mudar ao longo da vida útil de um sistema de uma edificação, o que evidencia a necessidade de se avaliar continuamente o desempenho dos sistemas instalados sob a perspectiva dos usuários.

A estrutura apresentada na Figura 1 enfatiza que os estudos sobre comportamento de usuário em edificações e a criação de sistemas de automação predial podem ser associados a fim de otimizar o desempenho das edificações atendendo às preferências de seus usuários. Inicialmente, ao se conhecer os principais aspectos impactantes nos ajustes dos EIS, mesmo que de uma população genérica, sistemas automatizados podem ser criados considerando-se aspectos relacionados aos ajustes dos EIS. Posteriormente, o próprio funcionamento do sistema automatizado pode ser uma importante fonte de informações para a melhoria de seus modelos de controle. Em outras palavras, a maneira como os usuários aceitam ou não (desfazem ajustes de sistemas automatizados) pode servir como feedback para aprimorar o funcionamento do sistema ao se considerar as preferências de seus usuários. Esse aspecto já foi apresentado na literatura como uma maneira de incluir a dimensão humana no ciclo do desempenho das edificações (BAVARESCO et al., 2019a). Desta forma, a presente revisão de literatura expõe que a combinação entre os resultados de monitoramento e modelagem de comportamento de usuário pode beneficiar o desenvolvimento de sistemas de automação predial. Ao se obter sistemas centrados nas preferências dos usuários, impactos positivos nos níveis de eficiência energética e de satisfação dos ocupantes das edificações são facilitados.

\section{Discussões}

Para sintetizar as informações apresentadas ao longo desta revisão de literatura, apresenta-se o Quadro 2 com o intuito de facilitar a comparação entre os principais pontos dos trabalhos revisados. Nele, os estudos são classificados em relação à técnica de monitoramento empregada, à modelagem escolhida, aos parâmetros apresentados como impactantes na abertura e fechamento dos EIS e ao programa computacional utilizado nas simulações. Com a síntese, espera-se obter um panorama geral dessa área, a fim de basear futuros estudos e avançar na compreensão sobre o comportamento dos usuários de escritório em relação aos ajustes dos EIS. Por fim, apresenta-se uma análise crítica em relação às principais informações obtidas com essa revisão de literatura.

Figura 1 - Ciclo do conhecimento sobre preferências de usuários de sistemas automatizados para controle de elementos internos de sombreamento

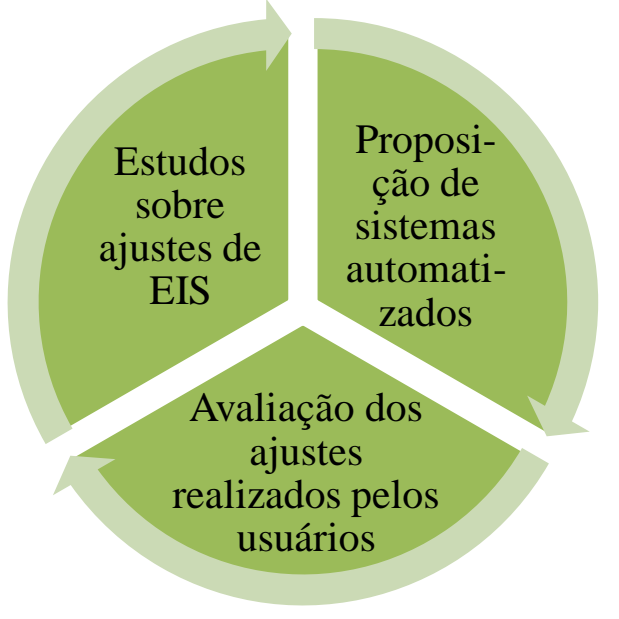

326 Bavaresco, M. V.; Ghisi, E. 
Quadro 2 - Síntese dos estudos revisados apresentando detalhes do método empregado1 (Continua...)

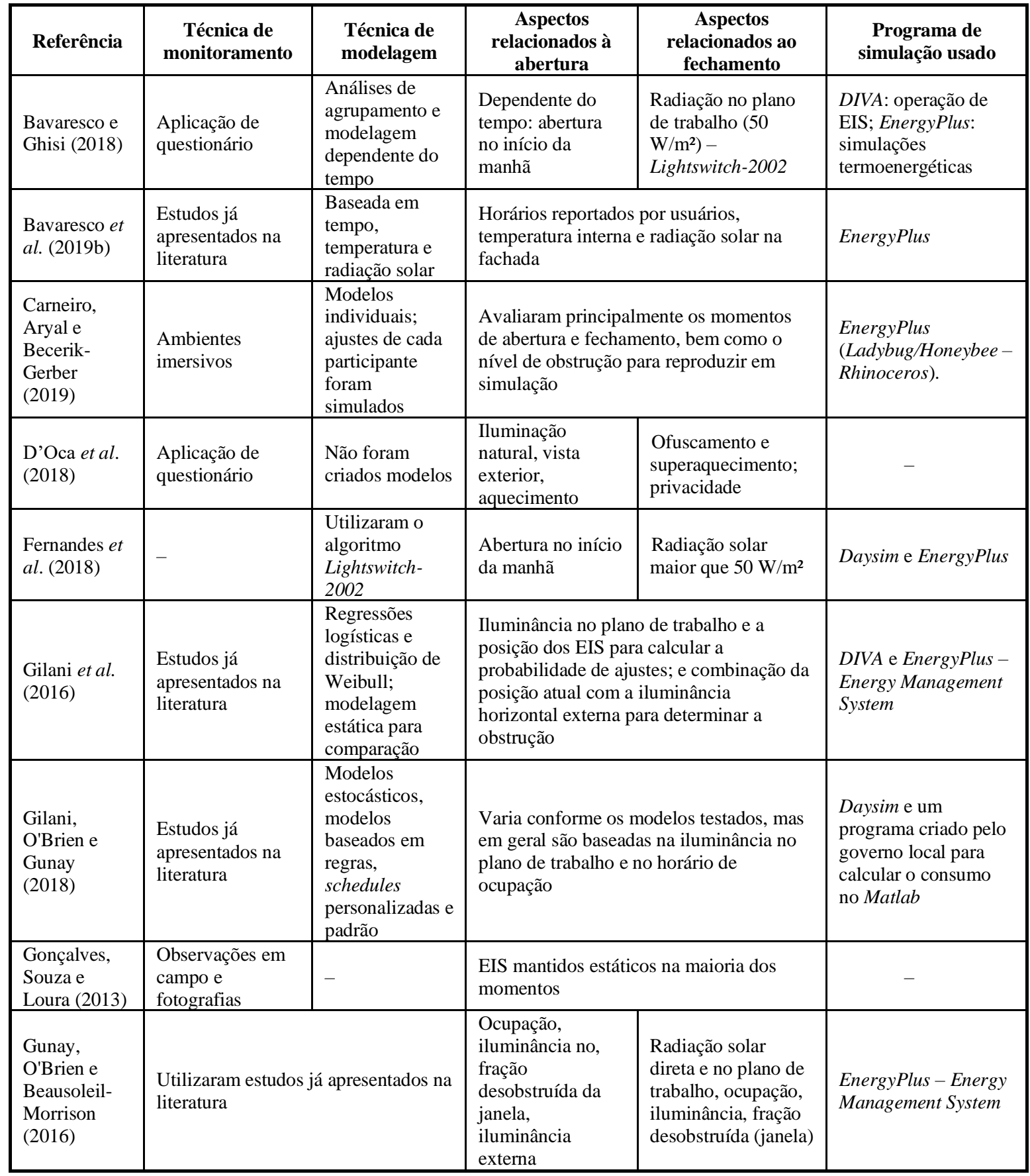


Quadro 2 - Síntese dos estudos revisados apresentando detalhes do método empregado1 (continuação)

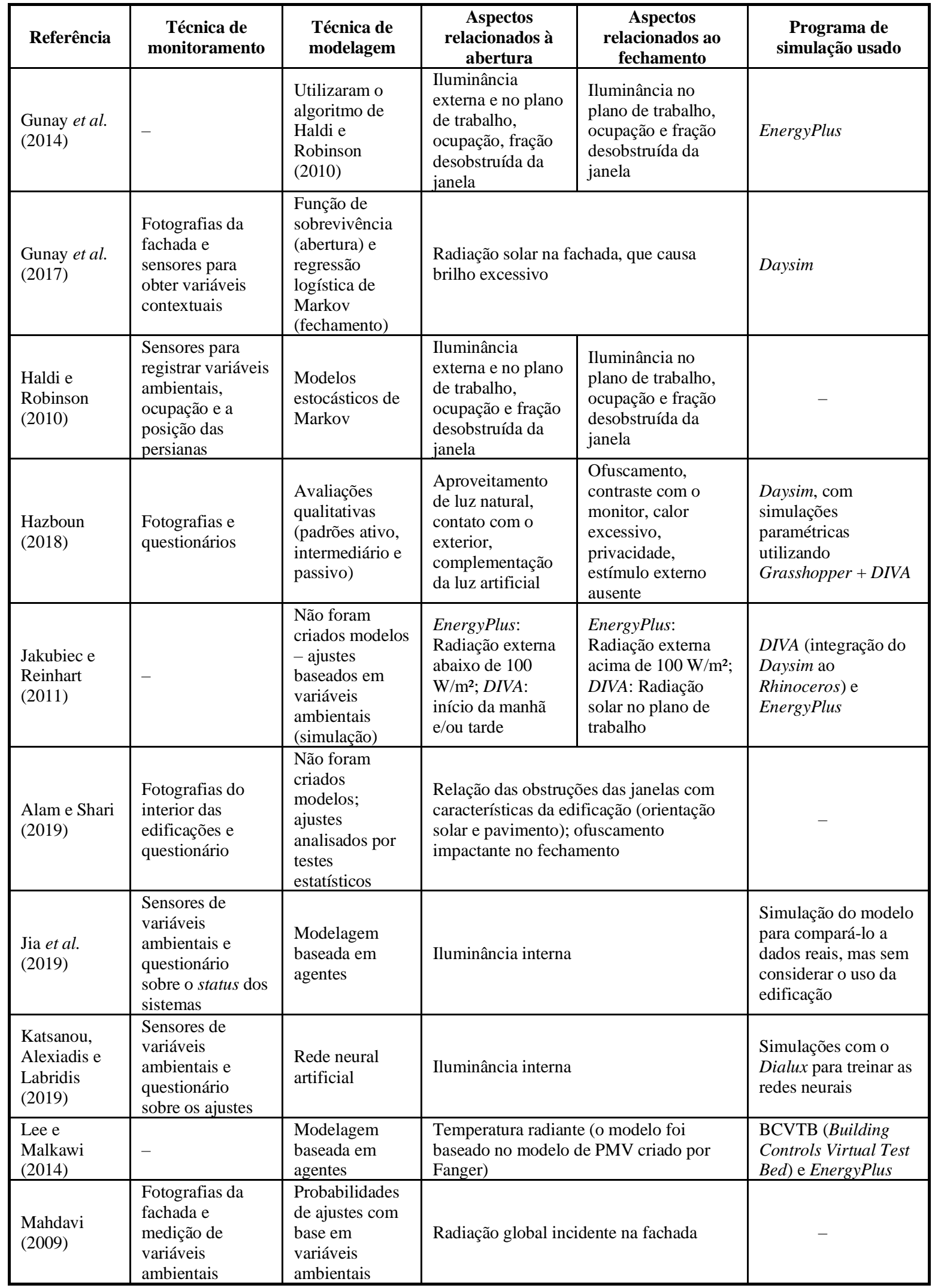


Quadro 2 - Síntese dos estudos revisados apresentando detalhes do método empregado1 (continuação)

\begin{tabular}{|c|c|c|c|c|c|}
\hline Referência & $\begin{array}{c}\text { Técnica de } \\
\text { monitoramento }\end{array}$ & $\begin{array}{l}\text { Técnica de } \\
\text { modelagem }\end{array}$ & $\begin{array}{c}\text { Aspectos } \\
\text { relacionados à } \\
\text { abertura }\end{array}$ & $\begin{array}{c}\text { Aspectos } \\
\text { relacionados ao } \\
\text { fechamento } \\
\end{array}$ & $\begin{array}{c}\text { Programa de } \\
\text { simulação usado }\end{array}$ \\
\hline $\begin{array}{l}\text { Nezamdoost } \\
\text { et al. }(2018)\end{array}$ & $\begin{array}{l}\text { Fotografias da } \\
\text { fachada }\end{array}$ & $\begin{array}{l}\text { Algoritmo para } \\
\text { estimar ajustes } \\
\text { dos EIS } \\
\text { baseado nos } \\
\text { níveis de } \\
\text { iluminância } \\
\text { vertical exterior }\end{array}$ & $\begin{array}{l}\text { Vista para o } \\
\text { exterior e } \\
\text { iluminância } \\
\text { vertical exterior }\end{array}$ & $\begin{array}{l}\text { Condições do céu, } \\
\text { tipo do EIS, } \\
\text { existência de } \\
\text { elementos externos } \\
\text { e iluminância } \\
\text { vertical exterior }\end{array}$ & $\begin{array}{l}\text { Propuseram o } \\
\text { algoritmo } \\
\text { Blindswitch-2018 } \\
\text { para simulações } \\
\text { computacionais }\end{array}$ \\
\hline $\begin{array}{l}\text { Nezamdoost } \\
\text { et al. }(2018)\end{array}$ & - & $\begin{array}{l}\text { Algoritmos } \\
\text { prévios: } \\
\text { Blindswitch-A, } \\
\text { Blindswitch-B, } \\
\text { LM-83-based } \\
\text { algorithm, } \\
\text { Lightswitch- } \\
2002\end{array}$ & \multicolumn{2}{|c|}{$\begin{array}{l}\text { Radiação externa, iluminância vertical na } \\
\text { fachada e radiação solar (o Lightswitch- } \\
2002 \text { considera a abertura dos EIS no } \\
\text { início da manhã; nos demais esse ajuste é } \\
\text { baseado nas variáveis ambientais) }\end{array}$} & $\begin{array}{l}\text { EnergyPlus e } \\
\text { Radiance }\end{array}$ \\
\hline $\begin{array}{l}\text { Ouf, Gunay e } \\
\text { O'Brien } \\
(2019)\end{array}$ & - & $\begin{array}{l}\text { Utilizaram o } \\
\text { algoritmo de } \\
\text { Haldi e } \\
\text { Robinson } \\
(2010) \\
\end{array}$ & $\begin{array}{l}\text { Iluminância } \\
\text { externa e no plano } \\
\text { de trabalho, } \\
\text { ocupação e fração } \\
\text { desobstruída }\end{array}$ & $\begin{array}{l}\text { Iluminância no } \\
\text { plano de trabalho, } \\
\text { ocupação e fração } \\
\text { desobstruída da } \\
\text { janela }\end{array}$ & Daysim \\
\hline $\begin{array}{l}\text { Ozcelik, } \\
\text { Becerik- } \\
\text { Gerber e } \\
\text { Chugh } \\
(2019)\end{array}$ & $\begin{array}{l}\text { Ambientes } \\
\text { imersivos }\end{array}$ & - & \multicolumn{2}{|c|}{$\begin{array}{l}\text { Combinação de temperaturas elevadas } \\
\left(26-27^{\circ} \mathrm{C}\right) \text { e ofuscamento provenientes de } \\
\text { radiação solar incidente }\end{array}$} & $\begin{array}{l}\text { Simulações realizadas } \\
\text { no ambiente imersivo }\end{array}$ \\
\hline $\begin{array}{l}\text { Sadeghi et al. } \\
\text { (2017) }\end{array}$ & $\begin{array}{l}\text { Aplicação de } \\
\text { questionários e } \\
\text { utilização de } \\
\text { sensores }\end{array}$ & $\begin{array}{l}\text { Abordagens } \\
\text { Bayesianas } \\
\text { (modelo } \\
\text { Bayesiano } \\
\text { multivariado e } \\
\text { modelo de } \\
\text { regressão } \\
\text { Bayesiana) } \\
\end{array}$ & $\begin{array}{l}\text { Iluminância no } \\
\text { plano de trabalho, } \\
\text { preferência de } \\
\text { iluminação, } \\
\text { posição e } \\
\text { preferência pela } \\
\text { vista }\end{array}$ & $\begin{array}{l}\text { Iluminância vertical, } \\
\text { preferência de } \\
\text { iluminação, relação } \\
\text { entre posição atual e } \\
\text { privacidade }\end{array}$ & - \\
\hline $\begin{array}{l}\text { Schweiker, } \\
\text { Hawighorst e } \\
\text { Wagner } \\
(2016) \\
\end{array}$ & \multirow{2}{*}{$\begin{array}{l}\text { Ambientes semi- } \\
\text { controlados } \\
\text { (câmaras } \\
\text { climáticas) e } \\
\text { questionários }\end{array}$} & \multirow{2}{*}{$\begin{array}{l}\text { Modelo de } \\
\text { regressão } \\
\text { logística }\end{array}$} & \multicolumn{2}{|c|}{$\begin{array}{l}\text { Temperatura do ar externo, radiação } \\
\text { global horizontal e traços da personalidade } \\
\text { dos participantes }\end{array}$} & - \\
\hline $\begin{array}{l}\text { Schweiker e } \\
\text { Wagner } \\
(2016)\end{array}$ & & & $\begin{array}{l}\text { Abertos no início } \\
\text { do dia no } \\
\text { experimento }\end{array}$ & $\begin{array}{l}\text { Temperatura } \\
\text { externa, temperatura } \\
\text { operativa, hora do } \\
\text { dia }\end{array}$ & - \\
\hline Yao (2014) & $\begin{array}{l}\text { Fotografia dos } \\
\text { ambientes e } \\
\text { medição de } \\
\text { variáveis } \\
\text { ambientais } \\
\end{array}$ & $\begin{array}{l}\text { Regressão } \\
\text { logística e } \\
\text { modelo } \\
\text { estocástico de } \\
\text { Markov } \\
\end{array}$ & \multicolumn{2}{|c|}{$\begin{array}{l}\text { Temperatura externa e radiação solar } \\
\text { vertical nas superfícies externas }\end{array}$} & $\begin{array}{l}\text { BCVTB (Building } \\
\text { Controls Virtual Test } \\
\text { Bed) e EnergyPlus }\end{array}$ \\
\hline $\begin{array}{l}\text { Zhang e } \\
\text { Barrett } \\
(2012)\end{array}$ & $\begin{array}{l}\text { Fotografia das } \\
\text { fachadas e } \\
\text { questionário }\end{array}$ & $\begin{array}{l}\text { Modelos } \\
\text { logísticos para } \\
\text { avaliar os } \\
\text { ajustes }\end{array}$ & \multicolumn{2}{|c|}{ Altitude solar e radiação solar } & - \\
\hline $\begin{array}{l}\text { Zhang e Lam } \\
\text { (2011) }\end{array}$ & - & $\begin{array}{l}\text { Aumentar a } \\
\text { carga térmica } \\
\text { nas estações de } \\
\text { aquecimento e } \\
\text { minimizar nas } \\
\text { estações de } \\
\text { resfriamento }\end{array}$ & \multicolumn{2}{|c|}{$\begin{array}{l}\text { Condição do céu (noite, céu nublado, } \\
\text { ensolarado ou muito brilho), } \\
\text { condicionamento do espaço (aquecimento } \\
\text { ou resfriamento) e status da ocupação } \\
\text { (ocupado ou desocupado) para determinar } \\
\text { a posição dos EIS }\end{array}$} & $\begin{array}{l}\text { Ptolemy para criar os } \\
\text { algoritmos de controle } \\
\text { e EnergyPlus para } \\
\text { simulações } \\
\text { termoenergéticas }\end{array}$ \\
\hline
\end{tabular}

A literatura enfatiza a importância em se estudar estratégias de sombreamento interno em diferentes localidades (HUANG; NIU; CHUNG, 2014). Entretanto, esta revisão de literatura concluiu que as avaliações nacionais ainda são escassas, o que mostra a clara necessidade de se ampliar o conhecimento 
produzido a fim de melhor compreender e representar os ajustes dos EIS. Apesar da dificuldade em se obter equipamentos precisos para monitorar os ajustes em campo, especialmente em países em desenvolvimento, a literatura evidencia a possibilidade de se empregar avaliações de baixo custo (como a aplicação de questionários) e combinar os dados obtidos a modelos mais complexos já criados em outros países (BAVARESCO; GHISI, 2019). Embora fatores como diferenças culturais e climáticas possam representar fontes de incertezas, essa abordagem ainda é apresentada na literatura como promissora quando comparada à desconsideração ou consideração estática dos elementos internos de sombreamento. Entretanto, é imprescindível que mais estudos sejam realizados para que pesquisadores e demais profissionais do setor de edificações apliquem os resultados no futuro (GUNAY; O’BRIEN; BEAUSOLEIL-MORRISON, 2016).

Avaliações subjetivas, como as de D'Oca et al. (2018), tendem a apresentar fatores como a apreciação da vista para o exterior e busca por privacidade como razões para abrir e fechar, respectivamente, os EIS. Ao contrário, avaliações baseadas em modelos criados a partir de medições, como as de Gunay, O’Brien e Beausoleil-Morrison (2016), tendem a apresentar parâmetros físicos como os responsáveis pelo controle dos EIS. Desta forma, um desafio para essa área em relação às pesquisas futuras é a combinação de fatores subjetivos e objetivos para obtenção de padrões de comportamento mais próximos da realidade. Aprofundar os estudos que combinam variáveis objetivas e subjetivas pode aumentar a precisão de modelos como os de Zhang e Barrett (2012), que consideram as probabilidades de ajuste a partir de parâmetros físicos como a altitude solar e os níveis de radiação. Nesse sentido, durante o cálculo das probabilidades, o registro de um usuário que fechou os EIS por motivos de privacidade em um dia com pouca radiação solar pode enviesar os resultados do modelo, se baseado apenas em fatores objetivos. Além disso, avaliações multimétodos de conforto estão ganhando atenção da comunidade científica, e um estudo recente mostrou que os ajustes dos EIS são os primeiros comportamentos adaptativos escolhidos por usuários submetidos a situações simultâneas de desconforto visual e térmico (OZCELIK; BECERIK-GERBER; CHUGH, 2019). De certa forma, essa conclusão sintetiza o que diversas pesquisas encontraram: usuários ajustam os EIS tanto por desconforto visual quanto por desconforto térmico. Portanto, quando ambos os critérios são insatisfatórios, os usuários tendem a ajustar os EIS rapidamente.

Modelos de controle ideais, considerando apenas as dinâmicas de troca de calor, podem ser vantajosos em relação aos aspectos de física da edificação. Entretanto, são dificilmente implementados em situações reais e, portanto, não são adequados para avaliar o impacto do controle de EIS no desempenho das edificações por meio de simulação. Sugere-se que esses modelos de controle sirvam como baseline para testar diferentes estratégias, uma vez que são criados a partir de condições ideais. De acordo com Yao (2014), modelos de controles de EIS ideais superestimam as reduções de consumo em simulações computacionais, sendo necessário considerar de maneira real os ajustes dos EIS. Quanto à realização de simulações computacionais, ressalta-se que a variável utilizada como motivadora para ajustes dos EIS pode determinar o programa computacional mais adequado para conduzir o estudo. Caso a iluminância no plano de trabalho seja definida como fator impactante ao fechamento dos EIS, é mais adequado que o algoritmo do Daysim/Radiance (seja com o plug-in DIVA ou o Honeybee) seja aplicado, uma vez que a literatura evidencia falhas no algoritmo do EnergyPlus para as simulações de iluminação. Ressalta-se que diversos estudos apresentados nessa revisão de literatura empregaram esses programas (GILANI; O’BRIEN; GUNAY, 2018; GUNAY et al., 2017; HAZBOUN, 2018; OUF; GUNAY; O’BRIEN, 2019). Apesar disso, alguns autores empregaram o EnergyPlus nas avaliações (BAVARESCO et al., 2019b; GUNAY et al., 2014). Apesar da possibilidade de superestimar os cálculos de iluminação natural, essa estratégia pode ser viável quando o objetivo é enfocar a análise no impacto do uso dos EIS no desempenho térmico de um modelo, uma vez que as simulações do EnergyPlus são precisas nesse aspecto. Outra estratégia comum na literatura é a combinação entre os algoritmos do Daysim e do EnergyPlus, a fim de acoplar de maneira mais precisa os resultados de simulações lumínicas às simulações termoenergéticas (BAVARESCO; GHISI, 2018; FERNANDES et al., 2018; GILANI et al., 2016; JAKUBIEC; REINHART, 2011; NEZAMDOOST; WYMELENBERG; MAHIC, 2018). Quanto ao EnergyPlus, a literatura evidencia a possibilidade de utilização do recurso Energy Management System para configurar controles mais avançados e baseados em diversos aspectos (GILANI et al., 2016; GUNAY; O’BRIEN; BEAUSOLEIL-MORRISON, 2016).

\section{Conclusões}

Neste artigo, revisou-se a literatura nacional e internacional, dos últimos dez anos, relacionada à operação de elementos internos de sombreamento (EIS) em ambientes de escritório. Ao longo do documento, apresentaram-se informações referentes ao monitoramento e modelagem dos ajustes dos EIS, bem como suas aplicações em simulação computacional e em sistemas de controle automatizados. Essas informações 
são importantes tanto para a elaboração de futuras pesquisas em relação à dimensão humana do consumo energético de edificações quanto para aplicações na indústria - seja em práticas de projeto ou de certificação de edificações. Portanto, espera-se que essa revisão de literatura consolide o conhecimento produzido até aqui e permita que, especialmente a literatura nacional, seja ampliada a fim de conhecer fatores relacionados aos ajustes dos EIS em diferentes cidades brasileiras. De maneira geral, concluiu-se que:

(a) diversas técnicas de monitoramento podem ser empregadas para avaliar os ajustes dos EIS em escritórios. Essa revisão de literatura encontrou a aplicação de observações em campo (walkthroughs), fotografias do interior e exterior de edificações, instalação de equipamentos de medição para avaliar os ajustes dos EIS e também variáveis ambientais e, por fim, aplicação de questionários;

(b) apesar de mais subjetiva em relação às observações ou medições com equipamentos apropriados, a aplicação de questionários pode fornecer informações valiosas sobre aspectos subjetivos que influenciam os ajustes dos EIS;

(c) empregar mais de uma técnica de monitoramento pode aumentar a confiabilidade dos resultados por combinar fatores subjetivos e objetivos relacionados aos ajustes dos EIS, permitindo maior detalhamento e confiabilidade para a criação de modelos de comportamento de usuário;

(d) as técnicas de modelagem são dependentes dos tipos de dados obtidos; portanto, é importante garantir a obtenção dos dados necessários a fim de obter a modelagem pretendida;

(e) os níveis de complexidade dos modelos criados não estão, necessariamente, relacionados à precisão das representações: a literatura evidencia que alguns algoritmos complexos criados a partir de bases de dados extensas podem superestimar os ajustes dos EIS;

(f) a literatura evidencia a possibilidade de se empregar modelos ou algoritmos criados em outros locais. Essa conclusão permite que avaliações pouco onerosas (como a aplicação de questionários) sejam realizadas e, a partir dos fatores apresentados como mais impactantes aos ajustes dos EIS, modelos já publicados sejam empregados em simulações computacionais. Essa é uma alternativa de baixo custo para facilitar a obtenção de design centrado nos usuários, e é bastante viável quando se considera a realidade de países em desenvolvimento;

(g) a escolha do programa computacional para realizar as simulações também está condicionada ao tipo de modelo empregado: se um modelo de ajuste de EIS baseado na iluminância interna é empregado, é preferível empregar o Radiance (ou outros programas baseados nele, como o Daysim ou o DIVA) ao invés do EnergyPlus;

(h) a literatura também sugere a utilização do recurso Energy Management System (EMS) no EnergyPlus para configurar padrões de controle de EIS avançados e reduzir incertezas quanto à operação. Além disso, a combinação de diferentes programas para que as deficiências de cada um sejam sanadas também foi encontrada na literatura;

(i) por fim, quanto mais estudada for a relação entre os usuários e os ajustes dos EIS, mais informações úteis para a criação de sistemas automatizados podem ser apresentadas aos profissionais do setor. Avaliar parâmetros objetivos e subjetivos relacionados aos ajustes pode facilitar a obtenção de sistemas centrados nos usuários; após isso, avaliações contínuas pelo próprio sistema automatizado (como modificações realizadas pelos usuários) podem ser interpretadas como feedback para o sistema, facilitando sua adequação contínua e garantindo níveis de satisfação adequados mesmo se os usuários do sistema mudarem ao longo de sua vida útil.

\section{Referências}

ALAM, S. M.; SHARI, Z. Occupants interaction with window blinds in a green-certified office building in Putrajaya, Malaysia. Journal of Design and Built Environment, v. 19, n. 1, 2019.

BALVEDI, B. F.; GHISI, E.; LAMBERTS, R. A review of occupant behaviour in residential buildings. Energy and Buildings, v. 174, p. 495-505, 2018.

BAVARESCO, M. V. et al. Technological innovations to assess and include the human dimension in the building-performance loop: A review. Energy and Buildings, v. 202, 2019a.

BAVARESCO, M. V. et al. Influence of control and finishing of internal blinds on the cooling energy consumption of buildings. In: CONFERENCE OF INTERNATIONAL BUILDING PERFORMANCE SIMULATION ASSOCIATION, Rome, 2019. Proceedings [...] Rome: IBPSA, 2019b. 
BAVARESCO, M. V.; GHISI, E. A low-cost framework to establish internal blind control patterns and enable simulation-based user-centric design. Journal of Building Engineering, 2019.

BAVARESCO, M. V.; GHISI, E. Influence of user interaction with internal blinds on the energy efficiency of office buildings. Energy and Buildings, v. 166, p. 538-549, maio 2018.

CARNEIRO, J. P.; ARYAL, A.; BECERIK-GERBER, B. Understanding the influence of orientation, timeof-day and blind use on user's lighting choices and energy consumption using immersive virtual environments. Advances in Building Energy Research, 2019.

CHEN, Y.; HONG, T.; LUO, X. An agent-based stochastic Occupancy Simulator. Building Simulation, v. 11, n. 1, p. 37-49, 2018.

COSTA, A. P. L. Avaliação ergonômica de escritórios panorâmicos de repartições públicas. Recife, 2011. 141 f. Dissertação (Mestrado em Design). Programa de Pós-Graduação em Design, Universidade Federal de Pernambuco, Recife, 2011.

D'OCA, S. et al. Contextual and behavioural factors influencing human-building interaction in university offices: a cross-cultural comparison. In: CLIMA 2019 - BUILT ENVIRONMENT FACING CLIMATE CHANGE, Bucharest, 2019. Proceedings [... [ Bucharest: REHVA, 2019a.

D'OCA, S. et al. Critical review and illustrative examples of office occupant modelling formalisms. Building Services Engineering Research and Technology, v. 40, n. 6, p. 732-757, nov. 2019 b.

D’OCA, S. et al. Human-building interaction at work: Findings from an interdisciplinary cross-country survey in Italy. Building and Environment, v. 132, p. 147-159, mar. 2018.

D’OCA, S. et al. Synthesizing building physics with social psychology: an interdisciplinary framework for context and occupant behavior in office buildings. Energy Research and Social Science, v. 34, p. 240-251, dez. 2017.

D’OCA, S.; HONG, T.; LANGEVIN, J. The human dimensions of energy use in buildings: a review. Renewable and Sustainable Energy Reviews, v. 81, p. 731-742, 2018.

DAY, J. Understanding controls, behaviors and satisfaction in the daylit perimeter office: a daylight design case study. Journal of Interior Design, v. 37, p. 17-37, 2012.

FERNANDES, L. O. et al. Potencial do uso da iluminação natural com dimmers e persianas automatizadas: estudo de edifício de pequeno porte com uso comercial para diferentes orientações em clima tropical. Ambiente Construído, Porto Alegre, v. 18, n. 2, p. 217-235, abr./jun. 2018.

GAETANI, I.; HOES, P. J.; HENSEN, J. L. M. Occupant behavior in building energy simulation: towards a fit-for-purpose modeling strategy. Energy and Buildings, v. 121, p. 188-204, 2016.

GILANI, S. et al. Use of dynamic occupant behavior models in the building design and code compliance processes. Energy and Buildings, v. 117, p. 260-271, abr. 2016.

GILANI, S.; O’BRIEN, W.; CARRIZO, J. S. Interpreting occupant-building interactions for improved office building design and operation. ASHRAE Transactions., v. 123, n. 2, p. 185-201, 2017.

GILANI, S.; O’BRIEN, W.; GUNAY, H. B. Simulating occupants' impact on building energy performance at different spatial scales. Building and Environment, v. 132, p. 327-337, mar. 2018.

GONÇALVES, C. C.; SOUZA, R. V. G.; LOURA, R. M. A influência dos usuários na eficiência energética de uma edificação - Estudo de caso do Laboratório de Conforto da UFMG. 2013, [S.1: s.n.], 2013.

GUNAY, H. B. et al. Development and implementation of an adaptive lighting and blinds control algorithm. Building and Environment, v. 113, p. 185-199, 15 fev. 2017.

GUNAY, H. B. et al. On adaptive occupant-learning window blind and lighting controls. Building Research and Information, v. 42, n. 6, p. 739-756, jan. 2014.

GUNAY, H. B.; O’BRIEN, W.; BEAUSOLEIL-MORRISON, I. Implementation and comparison of existing occupant behaviour models in EnergyPlus. Journal of Building Performance Simulation, v. 9, n. 6, p. 567-588, nov. 2016.

HALDI, F.; ROBINSON, D. Adaptive actions on shading devices in response to local visual stimuli. Journal of Building Performance Simulation, v. 3, n. 2, p. 135-153, jun. 2010. 
HAZBOUN, V. D. Desempenho da luz natural em ambientes com aberturas voltadas para leste considerando a influência dos usuários. Natal, 2018. 118 f. Dissertação (Mestrado em Arquitetura e Urbanismo) - Centro de Tecnologia, Universidade Federal do Rio Grande do Norte, Natal, 2018.

HEYDARIAN, A. et al. Immersive virtual environments, understanding the impact of design features and occupant choice upon lighting for building performance. Building and Environment, v. 89, p. 217-228, jul. 2015.

HUANG, Y.; NIU, J. L.; CHUNG, T. M. Simulation study of shading design performance in coolingdominant climates. In: $13^{\text {th }}$ INTERNATIONAL CONFERENCE ON INDOOR AIR QUALITY AND CLIMATE, Hong Kong, 2014. Proceedings [...] Hong Kong: ISIAQ, 2014.

JAKUBIEC, J. A.; REINHART, C. F. DIVA 2.0: integrating daylight and thermal simulations using rhinoceros 3D, DAYSIM and EnergyPlus. In: CONFERENCE OF INTERNATIONAL BUILDING PERFORMANCE SIMULATION ASSOCIATION, 12., Sydney, 2011. Proceedings [...] Sydney: IBPSA, 2011.

JIA, M. et al. A systematic development and validation approach to a novel agent-based modeling of occupant behaviors in commercial buildings. Energy and Buildings, v. 199, p. 352-367, set. 2019.

KATSANOU, V. N.; ALEXIADIS, M. C.; LABRIDIS, D. P. An ANN-based model for the prediction of internal lighting conditions and user actions in non-residential buildings. Journal of Building Performance Simulation, v. 12, n. 5, p. 700-718, set. 2019.

LEE, Y. S.; MALKAWI, A. M. Simulating multiple occupant behaviors in buildings: an agent-based modeling approach. Energy and Buildings, v. 69, p. 407-416, fev. 2014.

LIU, J.; YAO, R.; MCCLOY, R. An investigation of thermal comfort adaptation behaviour in office buildings in the UK. Indoor and Built Environment, v. 23, n. 5, p. 675-691, 2014.

MAHDAVI, A. Patterns and implications of user control actions in buildings. Indoor and Built Environment, v. 18, n. 5, p. 440-446, out. 2009.

NEZAMDOOST, A. et al. A human factors study to update a recently proposed manual blind use algorithm for energy and daylight simulations. In: ANNUAL CONFERENCE OF INDUSTRIAL ELECTRONICS SOCIETY, Washington D.C., 2018. Proceedings [...] Washington D.C.: IEEE, 2018.

NEZAMDOOST, A.; WYMELENBERG, K.; MAHIC, A. Assessing the energy and daylighting impacts of human behavior with window shades, a life-cycle comparison of manual and automated blinds. Automation in Construction, v. 92, p. 133-150, ago. 2018.

O'BRIEN, W.; GUNAY, H. B. The contextual factors contributing to occupants' adaptive comfort behaviors in offices - A review and proposed modeling framework. Building and Environment, v. 77, p. 77-87, 2014.

O'BRIEN, W.; KAPSIS, K.; ATHIENITIS, A. K. Manually-operated window shade patterns in office buildings: A critical review. Building and Environment, v. 60, p. 319-338, 2013

OUF, M. M.; GUNAY, H. B.; O’BRIEN, W. A method to generate design-sensitive occupant-related schedules for building performance simulations. Science and Technology for the Built Environment, v. 25, n. 2, p. 221-232, fev. 2019.

OZCELIK, G.; BECERIK-GERBER, B.; CHUGH, R. Understanding human-building interactions under multimodal discomfort. Building and Environment, v. 151, p. 280-290, mar. 2019.

RAMOS, G.; GHISI, E. Avaliação do cálculo da iluminação natural realizada pelo programa EnergyPlus. Ambiente Construído, v. 10, n. 2, p. 157-169, 2010.

REINHART, C. F. Lightswitch-2002: a model for manual and automated control of electric lighting and blinds. Solar Energy, v. 77, n. 1, p. 15-28, 2004.

SADEGHI, S. A. et al. A Bayesian modeling approach of human interactions with shading and electric lighting systems in private offices. Energy and Buildings, v. 134, p. 185-201, jan. 2017.

SCHWEIKER, M.; HAWIGHORST, M.; WAGNER, A. The influence of personality traits on occupant behavioural patterns. Energy and Buildings, v. 131, p. 63-75, nov. 2016.

SCHWEIKER, M.; WAGNER, A. The effect of occupancy on perceived control, neutral temperature, and behavioral patterns. Energy and Buildings, v. 117, p. 246-259, abr. 2016. 
STAZI, F.; NASPI, F.; D’ORAZIO, M. A literature review on driving factors and contextual events influencing occupants' behaviours in buildings. Building and Environment, v. 118, p. 40-66, jun. 2017

WAGNER, A.; O'BRIEN, W.; DONG, B. Exploring occupant behavior in buildings: methods and challenges. Cham: Springer International Publishing, 2017.

WANG, Z.; HONG, T.; JIA, R. Buildings.Occupants: a Modelica package for modelling occupant behaviour in buildings. Journal of Building Performance Simulation, v. 12, n. 4, p. 433-444, 4 jul. 2019.

YAN, D. et al. IEA EBC Annex 66: definition and simulation of occupant behavior in buildings. Energy and Buildings, v. 156, p. 258-270, 2017.

YAO, J. Determining the energy performance of manually controlled solar shades: A stochastic model based co-simulation analysis. Applied Energy, v. 127, p. 64-80, ago. 2014.

YOSHINO, H.; HONG, T.; NORD, N. IEA EBC annex 53: total energy use in buildings: analysis and evaluation methods. Energy and Buildings, v. 152, p. 124-136, 2017.

ZHANG, R.; LAM, K. P. Comparison of building load performance between first principle based and implementable shading control algorithms. Building Simulation, v. 4, n. 2, p. 135-148, jun. 2011.

ZHANG, Y.; BARRETT, P. Factors influencing occupants' blind-control behaviour in a naturally ventilated office building. Building and Environment, v. 54, p. 137-147, ago. 2012.

Mateus V. Bavaresco

Departamento de Engenharia Civil | Universidade Federal de Santa Catarina | Rua João Pio Duarte da Silva, 205, Córrego Grande | Florianópolis - SC - Brasil | CEP 88040-900 | Tel.:(48) 3721-5184 | E-mail: bavarescomateus@gmail.com

Enedir Ghisi

Departamento de Engenharia Civil | Universidade Federal de Santa Catarina | Tel.: (48) 3721-2115 | E-mail: enedir.ghisi@ufsc.br

\author{
Ambiente Construído \\ Revista da Associação Nacional de Tecnologia do Ambiente Construído \\ Av. Osvaldo Aranha, $99-3^{\circ}$ andar, Centro \\ Porto Alegre - RS - Brasil \\ CEP $90035-190$ \\ Telefone: +55 (51) 3308-4084 \\ Fax: +55 (51) 3308-4054 \\ www.seer.ufrgs.br/ambienteconstruido \\ E-mail: ambienteconstruido@ufrgs.br
}

